\title{
Aaron Swartz: bandido ou herói do acesso aberto?
}

\author{
Murilo Bastos da Cunha \\ Universidade de Brasília, Faculdade de Ciência da Informação, Brasília, DF, Brasil \\ murilobc@unb.br
}

DOI: https://doi.org/10.26512/rici.v13.n2.2020.31711

Recebido/Recibido/Received: 2020-03-31

Aceitado/Aceptado/Accepted: 2020-05-22

Resumo: O editorial analisa o papel de Aaron Swartz, um ativista e inovador tecnológico, pelo download de milhões de artigos de periódicos do banco de dados JSTOR. O JSTOR retirou a queixa contra Swartz depois que ele devolveu os arquivos digitais dos artigos. Entretanto, o processo não parou por aí, pois o judiciário decidiu que o acusado deveria, mesmo assim, responder pelos seus atos no tribunal. É possível que esse julgamento tenha provocado o suicídio do jovem de 26 anos. Na época atual, em meio à terrível pandemia da covid-19, o acesso rápido e universal à informação científica fica prejudicado pela legislação vigente dos direitos autorais. Para vencer o coronavírus é vital que mais pesquisas e dados sejam disponibilizados ao público. Pode-se afirmar, que, depois do covid-19, nada será igual como antes. A comunicação científica também passará por reformas e, paulatinamente, o jovem ativista será considerado um herói do acesso aberto! Além disso, são comentados os artigos incluídos no segundo número de 2020 da Revista Ibero-Americana de Ciência da Informação.

Palavras-chave: acesso aberto. Covid-19. Aaron Swartz. Comunicação científica.

\section{Aaron Swartz: ¿bandido o héroe de acceso abierto?}

Resumen: El editorial analiza el papel de Aaron Swartz, un activista e innovador tecnológico, descargando millones de artículos de revistas de la base de datos JSTOR. JSTOR retiró la denuncia contra Swartz después de que devolviera los archivos digitales de los artículos. Sin embargo, el proceso no se detuvo allí, ya que el poder judicial decidió que el acusado aún debería ser considerado responsable de sus acciones en los tribunales. Es posible que este juicio conduzca al suicidio de la joven de 26 años. En la actualidad, en medio de la terrible pandemia de covid-19, el acceso rápido y universal a la información científica se ve obstaculizado por la legislación vigente en materia de derechos de autor. Para vencer al coronavirus, es vital que más investigación y datos estén disponibles para el público. Se puede decir que, después del covid-19, nada será igual que antes. La comunicación científica también se someterá a reformas y, gradualmente, jel joven activista será considerado un héroe de acceso abierto! Además, se comentan los artículos publicados en el segundo número de 2020 de la Revista Iberoamericana de Ciencias de la Información.

Palabras clave: acceso abierto. Covid-19, Aaron Swartz. Comunicación científica.

\section{Aaron Swartz: bandit or open access hero?}

Abstract: The editorial analyzes the role of Aaron Swartz, an activist and technological innovator, by downloading millions of journal articles from the JSTOR database. JSTOR withdrew the complaint against Swartz after he returned the digital archives of the articles. However, the process did not stop there, as the judiciary decided that the accused should still be held responsible for his actions in court. It is possible that this trial led to the suicide of the 26-year-old. At the present time, during the terrible covid-19 pandemic, rapid and universal access to scientific information is hindered by current copyright legislation. To beat the coronavirus, it is vital that more research and data are made available to the public. It can be said that, after the covid-19, nothing will be the same as before. Scientific communication will also undergo reforms and, gradually, the young activist will be considered a hero of open access! In addition, 
the articles published in the second issue of 2020 of the Ibero-American Journal of Information Science are commented.

Keywords: open access. Covid-19. Aaron Swartz. Scientific communication.

Caro leitor,

Em 20 de julho de 2011, nova anos atrás, publiquei uma postagem (CUNHA, 2011) no blog "A Informação", do qual colaborei por muitos anos. Esta postagem foi baseada numa notícia divulgada nessa mesma data, por Scott Jashik (2011), mostrando que

Um júri federal condenou Aaron Swartz - um ativista e inovador tecnológico pelo roubo de milhões de artigos de revistas por meio da conta assinada pelo Massachusetts Institute of Technology no banco de dados JSTOR.

$O$ veredicto

O veredicto descreveu esforço de Swartz para utilizar uma conta de convidado do MIT para fazer o download dos artigos, mesmo que ele não tivesse o direito legal de fazê-lo. Nesse tempo ele era afiliado à Harvard University, podendo então ler os artigos. Ele pode ter uma pena na prisão por $\mathbf{3 5}$ anos e uma multa de até um milhão de dólares. (JASNIK, 2011, grifo nosso).

Mas quem foi Aaron Swartz? Norte-americano, nascido em 1986, cometeu suicídio em 11 de janeiro de 2013, em Nova York. Nas semanas seguintes, a mídia em todo o mundo, comentou esse triste episódio. Em Portugal, Claudia Bancaleiro (2013), apontou que

O suicídio ocorreu a poucas semanas do seu julgamento pela acusação de fazer o download ilegal de 4,8 milhões de documentos científicos e literários (quase a totalidade do arquivo) da plataforma na Internet intitulada JSTOR, através da rede do MIT. [...]

A família de Swartz divulgou um comunicado após a morte, no qual considerou que a decisão do jovem foi "um produto de um sistema de justiça criminal repleto de intimidações". Os familiares criticam as autoridades judiciais por terem acusado Swartz por "um alegado crime que não fez vítimas", alargando as responsabilidades no suicídio ao MIT.

[...] o presidente do MIT publicou uma nota no site da instituição, no qual lamenta a morte de Aaron Swartz e anuncia um inquérito interno para determinar o papel do MIT na decisão trágica do jovem. No comunicado, L. Rafael Reif começa por realçar a "brilhante criatividade e idealismo" de Swartz e por prestar condolências à família. "Quero expressar muito claramente que eu e todos no MIT estamos extremamente tristes com a morte deste jovem promissor, que tocou a vida de tantos. É-me doloroso pensar que o MIT tenha assumido qualquer papel numa série de acontecimentos que terminaram em tragédia", escreve L. Rafael Reif.

O responsável sublinha que este é o "momento de todos os envolvidos reflectirem sobre as suas acções, incluindo o MIT". A instituição vai assim lançar uma investigação para verificar todas as decisões tomadas desde que foi registado o primeiro indício de actividade suspeita nos seus dados em 2010, alegadamente da autoria de Swartz, até agora. 
O banco de dados JSTOR retirou a queixa contra Swartz depois que ele devolveu os arquivos digitais dos artigos. Entretanto, o processo não parou por aí, pois o judiciário decidiu que o acusado deveria, mesmo assim, responder pelos seus atos no tribunal. É possível que esse julgamento, que seria realizado dentro de poucas semanas, tenha provocado o ato extremo do jovem de 26 anos.

Swartz foi um jovem prodígio da informática. Com 14 anos ele foi um dos criadores do agregador de notícias RSS, programa que possibilita o internauta a receber, de forma regular, notícias sobre os mais variados assuntos de sua escolha. Além disso, ele foi um dos responsáveis pela rede social Reddit [https://www.reddit.com/ ], voltada para o compartilhamento de ligações para conteúdo na internet.

Ele também foi um dos criadores da organização Demand Progress [https://demandprogress.org/about/ ], ligada nas temáticas voltadas para a liberdade civil, direitos humanos e reforma governamental, e sempre com a crença de que a informação deve ser compartilhada e estar disponível para o bem da sociedade.

É famoso o seu documento, divulgado em julho de 2008, intitulado "Manifesto da Guerrilha do Livre Acesso" (SWARTZ, 2008), no qual afirmou que "A informação é poder. Mas, tal como acontece com todo o poder, há aqueles que querem guardá-lo para si." Aqui, novamente, reafirmou o seu pensamento de que todos tivessem acesso aos artigos científicos publicados online e apelava ao fim do que considerava "um roubo privado da cultura pública".

Voltando à minha postagem de 2011, inseri o seguinte comentário:

É sabido que a maioria dos sistemas de bancos de dados e bibliotecas digitais possui instrumentos para coibir a cópia exagerada por parte dos seus consulentes.

Esse tipo de controle, também denominado de gestão de direitos autorais (Digital Rights Management, DRM, em inglês) é essencial notadamente quando o usuário-final possui acesso a esses sistemas por meio de contratos ou autorizações legais que geralmente envolvem pagamentos pelo acesso à informação. A função básica do DRM é monitorar o acesso a conteúdos digitais e, ao mesmo tempo, assegurar e administrar os direitos autorais sobre esses conteúdos pelo ângulo do detentor desses direitos.

Já sob o ponto de vista de inúmeros consumidores, especialmente da Free Software Foundation, o termo DRM deveria ser Digital Restrictions Management (Gestão de restrições digitais)! Optando por uma das acepções, é pacífico que ambas permitem definir parâmetros e controlar conteúdos informacionais digitais com níveis de restrições.

Assim, os nossos usuários devem ser informados desse detalhes legais e as possíveis implicações decorrentes do uso inadequado (ou ilegal) desses acessos.

Mas, qual seria a resposta à indagação feita no título deste editorial [Aaron Swartz bandido ou herói do acesso aberto]? Na época atual, em meio à terrível pandemia do novo coronavírus, o acesso rápido e universal à informação científica fica prejudicado pela legislação 
vigente dos direitos autorais. Para vencer o coronavírus é vital que mais pesquisas e dados sejam disponibilizados ao público. É sabido que algumas dos grandes players editoriais, como a Elsevier, abriram temporariamente o acesso aos documentos, normalmente pagos, que tratem do tema covid-19. Muitos desses documentos certamente são das áreas biomédicas. Entretanto, a busca para combater e mitigar os impactos do vírus precisa contar com pesquisas das mais diversas áreas. Isto foi bem assinalado por David Matthews (2020) ao escrever que

Existem muitas disciplinas diferentes que podem contribuir", [...] não apenas em áreas de grande relevância como virologia e epidemiologia. "Há coisas que vêm de matemática, engenharia [e mais]."

Portanto, é possível que essa "abertura" seja menor do que a necessária para atender às demandas dos pesquisadores - a luta atual certamente envolve especialistas de inúmeras áreas. Existe ainda a necessidade de uma abertura contínua. $O$ que se espera para o mundo que há por vir? A ciência aberta é o futuro da ciência. Em uma próxima epidemia, como será a resposta científica a ela se dados de pesquisa relacionados já estivessem sido abertos?

Concluindo, em resposta ao título provocativo contido neste texto, pode-se afirmar que depois do covid-19 nada será igual como antes. Paradigmas serão mudados. É possível que a morte do Aaron Swartz não será em vão, isto é, a comunicação científica também passará por reformas e, paulatinamente, o jovem ativista será considerado um herói do acesso aberto!

Neste segundo número da RICl em 2020, foram selecionados para publicação 16 artigos. Boa leitura e até o nosso próximo número!

\section{Referências}

BANCALEIRO, Cláudia. MIT investiga responsabilidade na morte de Aaron Swartz. Público, Lisboa, 13 janeiro 2013. Disponível em: https://www.publico.pt/2013/01/14/tecnologia/noticia/mit-investiga-responsabilidade-namorte-de-aaron-swartz-1580668 Acessado em: 20 de abril de 2020.

CUNHA, Murilo Bastos da. O ativista que exagerou nos downloads. A Informação, 20 de julho de 2011. Disponível em: http://a-informacao.blogspot.com/search/label/biblioteca\%20digital Acesso em: 31 de março de 2020.

JASCHIK, Scott. Unusual_indictment_for_alleged_theft_of_JSTOR_journal_articles. Inside Higher Education, July 20, 2011. Disponível em: http://www.insidehighered.com/layout/set/print/news/2011/07/20/unusual indictment for alleged theft of jstor journal articles Acesso em: 20 jul. 2011. 
MATTHEWS, David. Coronavirus article free access 'doesn't go far enough'. The Higher Education, April 14, 2020. Disponível em:

https://www.timeshighereducation.com/news/coronavirus-article-free-access-doesnt-go-farenough Acessado em: 25 abril de 2020.

SWARTZ, Aaron. Guerrilla Open Acess Manifesto. Disponível em:

https://archive.org/details/GuerillaOpenAccessManifesto/mode/2up Acessado em: 20 de abril de 2020. 